\title{
A sense of balance
}

\section{Fiona Stuart-Wilson} talks to Jonathan Wood, Director of Operations with Dencare, about the importance of embracing change in the fast-moving dental world.

\section{Articles that would previously have appeared in the $B D$ J supplement Dental Business will now be appearing in the $B D J$.}

Tonathan Wood never meant to be a dentist. Looking at his biography to date it also looks as if he never meant to be a manager either — but he is now Director of Operations with Dencare, one of the major Bodies Corporate and one of the people you have to convince your practice is worth buying if you are looking to sell up to this particular corporate. On the face of it, to many dentists he is ideally qualified for the job, with a career in general practice and six years as a director of a major capitation scheme behind him. I was interested to learn his views as a manager on management and the profession's future. I was to learn that he has clear views and is not afraid of expressing them.

Jonathan Wood's career was originally destined to be a naval one. He went to nautical school and had a place at Dartmouth which he had to give up as he failed the rigorous medical examination. $\mathrm{He}$ ended up as a research technician at a veterinary college, but 'I got bored and lost direction.' He 'got passionate about dentistry after a course of treatment' and ended up with a place at dental school at the age of 25. 'Passionate' might be an unusual word for some to choose, but it is clear that he is a man with strong views springing from clear and passionate convictions. These views spread to almost all areas of dentistry and dental business, and with his pedigree, he speaks not just with conviction but with experience, although he is still a young man. After dental school he was keen to be in a progressive practice. $\mathrm{He}$ joined what he thought was such a practice in Macclesfield as an associate, and built up the NHS part of the practice, using hygienists. 'I was committed to prevention even then.' With the (some would say typical) view of many associates of 'how much is the principal making out of us?', he bought into the practice. 'I came down to earth when I made less as a principal than as an associate! In 1986 we made the initial decision to go private, and changed our opening hours and attracted new patients.' That same year saw him researching the private market intensively. 'At that stage I wasn't convinced by any of the schemes - including Denplan.' Part of that research took him to presentations by people such as Ken James and Colin Hall Dexter. 'I realised that if you follow the rules it works like a dream.'

In 1988 he 'dabbled with a conversion' then took the plunge in 1990 with a full Denplan conversion. 'I also got involved in the LDC, and was a national representative'. Shortly afterwards in 1992 he was approached to join Denplan.

'It was a real lifestyle decision when I was offered the job. The practice was now delivering the right profits, but I thought in ten years time will I wonder what the job would have been like?' The answer was clearly yes, as in 1992 he joined Denplan as a director and stayed with Denplan for six years. In 1998 Jonathan joined Dencare where he is Director of Operations.

Such career choices have at each stage presented opportunities for great personal change. This is something he clearly relishes, and this enthusiasm and acceptance of change is something he sees important for the profession. He is unequivocal in his views. 'Everyone has to think about change. Dentists have to accept that they need to look at everything they do and recognise that at some point it has to change. From that they can make decisions 
about what patients of the future are going to need, how they are going to demonstrate their compliance with clinical governance or whatever. Very importantly dentists have got to become proud of what they do and expect funders to fund it appropriately.'

He also points out that we may have to think differently in terms of what we mean by quality. 'Quality is not about how good the margins are or how quickly the patient was seen.' For Jonathan, quality is far more deeply ingrained in all of the practice's processes than that. 'Practices need an outstanding documentable audit process covering a whole range of issues, clinical governance, MDD labs, nurses' registration, health and safety, COSHH, working practices. Frankly, even the best in practices need to know where their strengths and weaknesses lie. Why? Because things can change or they haven't addressed some detail. That means quality issues aren't being addressed.'

And for Jonathan Wood, true quality is also about embracing change and recognising who or what is driving the changes. 'One of the key issues for dentistry is that the profession must recognise that patients will drive the agenda supported by medical and consumer organisations. This means we must think carefully about self-regulation. It's self-regulation versus control. If you want self-regulation, you need to be putting in place enough to demonstrate you're doing it right. You have to be demonstrating responsibility, and in the past the balance between freedom and responsibility in the profession may not always have been appropriate.' Although these may seem harsh words, he is, how-

ever, supportive of the profession

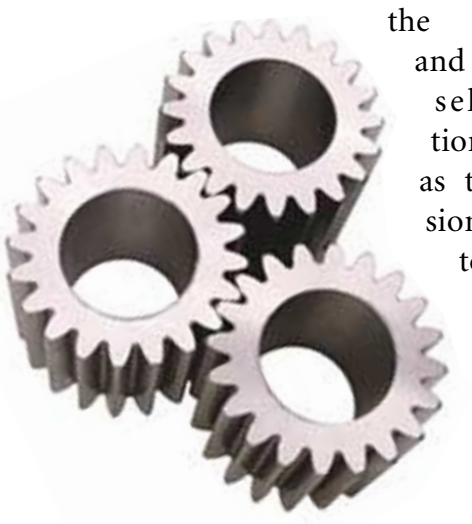
and its right to self-regulation - as long as the profession is ready to embrace change, it seems.

'In my view, the profession

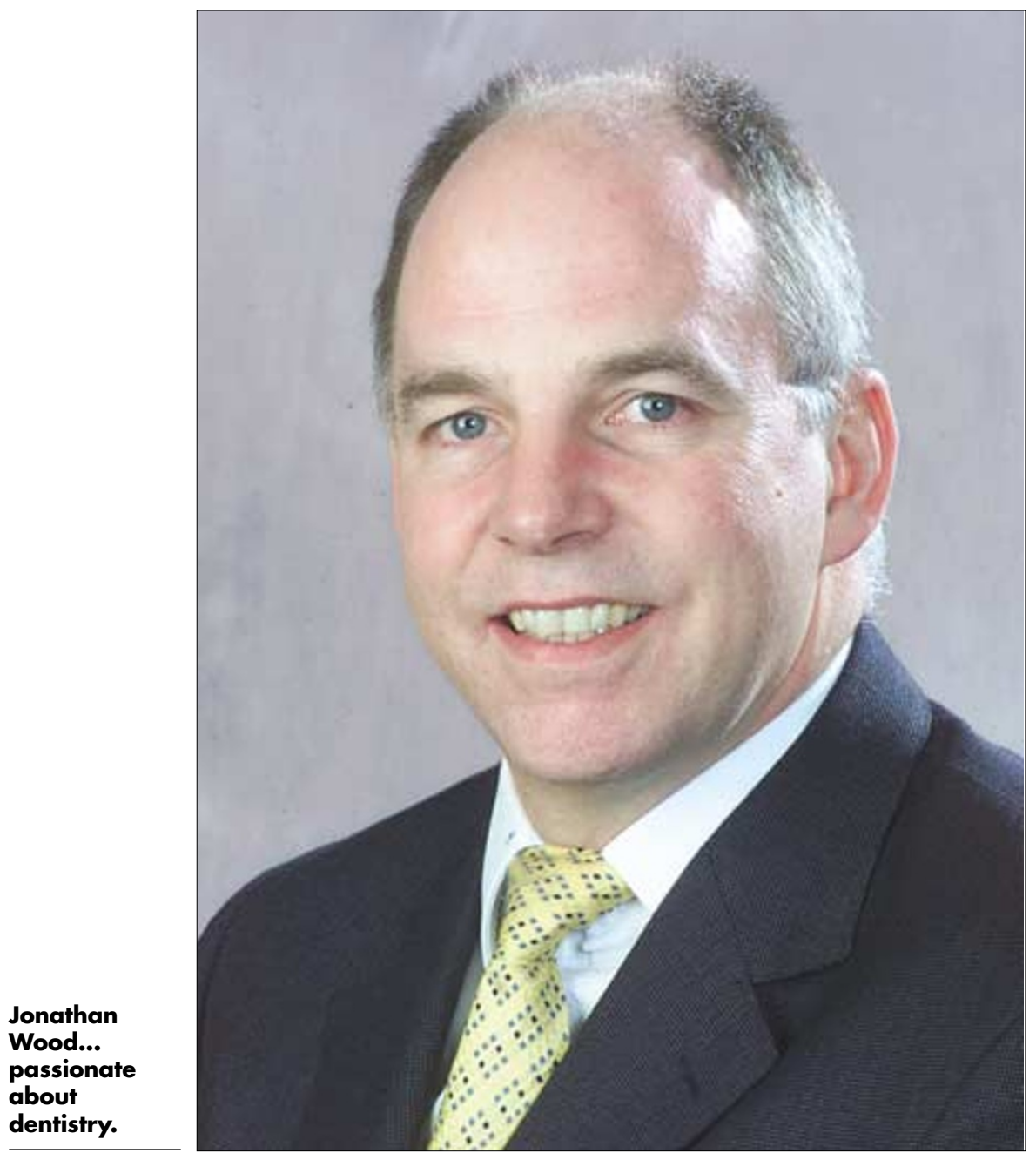

must review the professionals but some working practices which might seem right for the profession may not still be appropriate. You need to push hard to get people to see and remember that a new way might be a good one.'

So what does Jonathan consider that Bodies Corporate and their structure offer the practice and the professional? 'My personal belief is that practices want to rely on bodies, whether commercial or professional to facilitate the labelling of practices for the patients.

'Balance that with the fact that the new drivers for dentistry are demonstrating an appropriate balance between clinical care, availability of the service and value for money. In Dencare there is a business management structure which reviews practices regularly to ensure effectiveness of all three.' He clearly believes that the way dentists work as managers of their practices is at the heart of practice success.

He goes on to outline an approach, which seems to be almost worryingly simple. 'We have a tri-partite approach. We look for profitability, the right service to attract patients and make the patients feel that they are getting value for money. Profitability is about providing the right service to the patient and making the patient feel the charges are value for money. Whichever of these three is out of kilter alters the other two. So we're looking for quality of care, quality of service, quality of earning/profitability - and that's not your earnings (as a dentist). They are practice earnings and dentists interested in running successful businesses must see it as the practice earnings'.

One of the benefits that he sees of the introduction of PCDs is a more coherent approach to patient care - and a greater value placed on their contribution. 'It does mean that dentists will have to develop more leadership skills. Dentists often don't recognise the value of the team - they see themselves making every decision, clinical 
and operational.' I notice that clinical quality alone has not been included in this equation, but his next response makes clear that appropriate clinical quality lies at the heart of what he is looking for. In fact, his explanation of the Dencare philosophy appears to be a blend of the manager and the professional speaking. 'At Dencare we aim for better services for patients which are well understood and represent value for money.' The link between clearly defined services, quality and patient understanding is obviously important to Jonathan Wood. He believes that without clear signposts and explanations for patients, the perception of value for money is a difficult one for them to understand. He attributes some of their confusion to confusion amongst the dental profession itself. 'There is still a lack of clarity about the difference between NHS and private. The patient has no knowledge on which to decide what 'private' means, and dentists are restricted by what they THINK they can say about the NHS brand.' As he recognises this causes problems, what does he see as the role of capitation schemes?. His reply is suitably diplomatic. 'Capitation is a useful alternative payment system. It's a challenge for some practices to think 'one way or the other' and it helps some practices to provide a useful range of choices for patients. For many practices capitation remains a useful driver for conversion.'

So what is the main difference now and when he was in practice? Jonathan is thoughtful. His response again focuses on the dentist's management behaviour. 'I have a much clearer view of how one has to be to manage a balanced process for the patient. There is a risk that you can become entrenched in seeing things as a dentist. I still had a very dentist-oriented approach. I'm much tougher now. The things you want to have aren't always easy to get. You have to break moulds to create change.'

He is acutely honest in his next remarks. 'I've had varying degrees of success with my time with Denplan and Dencare. To be a real manager rather than a professional you have to be beaten up sometimes. There's no easy way to learn.

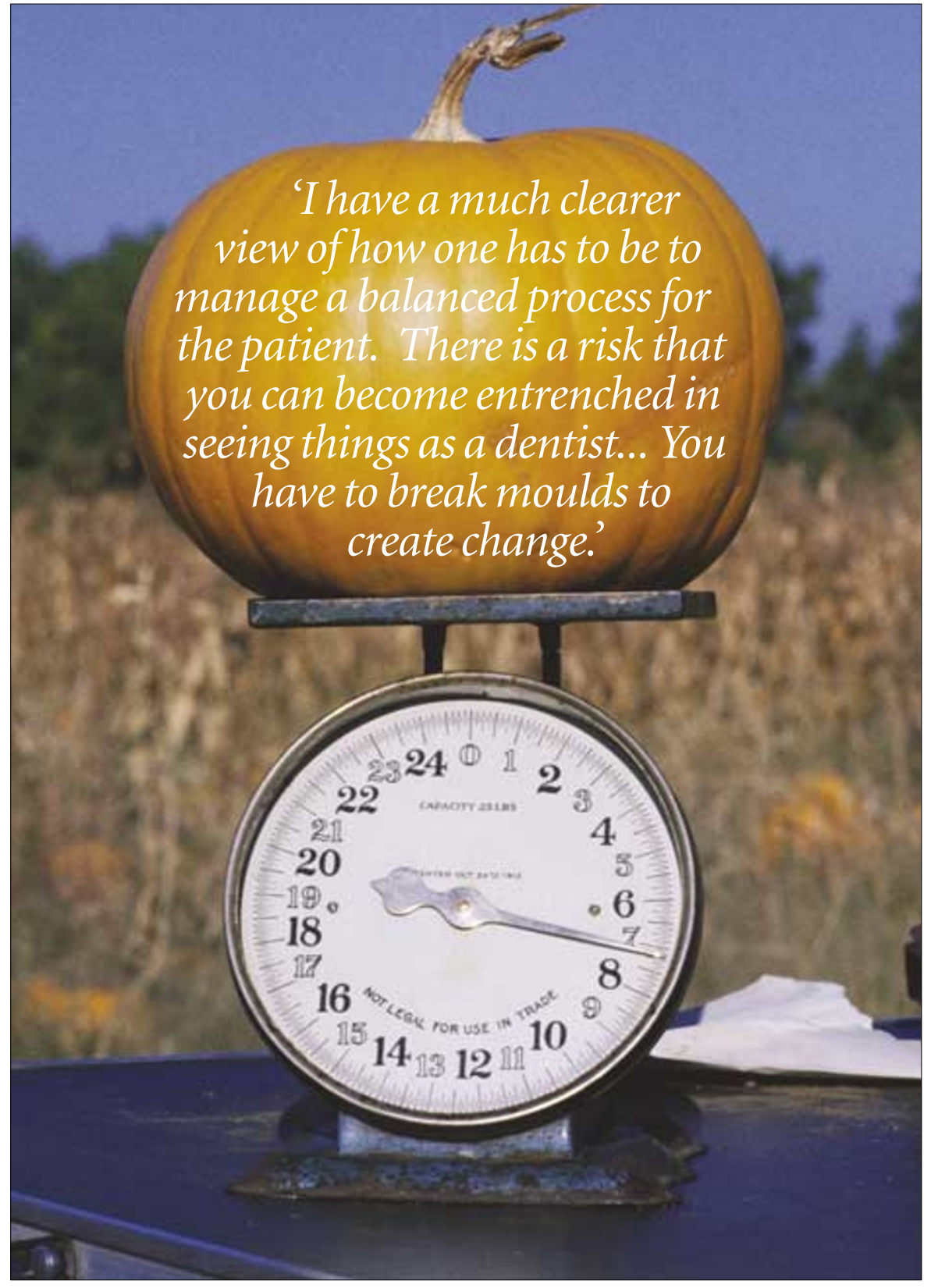

'If I had my time in practice again then processes and structure would be an issue. I'd be in a light industrial unit, not a threestorey Victorian house. I'd choose the right environment for patients and patient flow. I'd be creating a practice brand, with patients more loyal to the practice. That means practice image is more important than the individual dentists.'

It has been an interesting interview, and as we close, I realise that perhaps the biggest change for the ex-dentist sitting with me has been the move from the profession-centred approach to a patientcentred one.

After all, I reflect, perhaps this is how he sees all of the latest round of profession initiatives, clinical governance, quality standards and the rest - as a the drive towards better patient care. Better patient care? Clearer expectations? Better dental business? 